PEDRO DE MOURA ALBUQUERQUE DE OLIVEIRA

\title{
RECONFIGURAÇÃO CONCEITUAL DA RESPONSABILIDADE CIVIL PELO DIREITO DIGITAL?
}

\author{
Dissertação de Mestrado \\ Orientador: Professor Associado Dr. Juliano Souza de Albuquerque Maranhão
}

UNIVERSIDADE DE SÃO PAULO

FACULDADE DE DIREITO

SÃO PAULO-SP

2018 
PEDRO DE MOURA ALBUQUERQUE DE OLIVEIRA

\section{RECONFIGURAÇÃO CONCEITUAL DA RESPONSABILIDADE CIVIL PELO DIREITO DIGITAL?}

Dissertação apresentada à Banca Examinadora do Programa de Pós-Graduação em Direito, da Faculdade de Direito da Universidade de São Paulo, como exigência parcial para obtenção do título de Mestre em Direito, na Área de Concentração Filosofia e Teoria Geral do Direito, sob orientação do Professor Associado Dr. Juliano Souza de Albuquerque Maranhão.

\section{UNIVERSIDADE DE SÃO PAULO \\ FACULDADE DE DIREITO \\ SÃO PAULO-SP \\ 2018}


Autorizo a reprodução e divulgação parcial deste trabalho, por qualquer meio convencional ou eletrônico, para fins de estudo e pesquisa, desde que citada a fonte.

Oliveira, Pedro de Moura Albuquerque de

Reconfiguração conceitual da responsabilidade civil pelo direito digital? / Pedro de Moura Albuquerque de Oliveira ; orientador Juliano Souza de Albuquerque Maranhão -- São Paulo, 2018.

$139 \mathrm{p}$.

Dissertação (Mestrado - Programa de Pós-Graduação em Filosofia do Direito e Teoria Geral do Direito) - Faculdade de Direito, Universidade de São Paulo, 2018.

1. Reconfiguração conceitual. 2. Responsabilidade civil. 3. Direito digital. 4. Inferencialismo. 5. Metáforas. I. Maranhão, Juliano Souza de Albuquerque, orient. II. Título. 
Nome: Pedro de Moura Albuquerque de Oliveira

Título: Reconfiguração conceitual da responsabilidade civil pelo direito digital?

Dissertação apresentada à Faculdade de Direito da Universidade de São Paulo, para concorrer ao título de Mestre, pelo curso de Pós-Graduação em Filosofia e Teoria Geral do Direito.

\section{Banca Examinadora}

Professor Associado Doutor Juliano Souza de Albuquerque Maranhão (Orientador)

Professor:

Julgamento:

Professor:

Julgamento:

Professor:

Julgamento:
Instituição:

Assinatura:

Instituição:

Assinatura:

Instituição:

Assinatura: 


\section{AGRADECIMENTOS}

À Isabela, minha querida esposa, pelo amoroso companheirismo, apoio e compreensão, sem os quais completar esta jornada não teria sido possível.

À Claude, minha mãe, exemplo de força, carinho e retidão, fonte inesgotável de inspiração para novos desafios. Aos meus queridos irmãos Flora, Antônio e Luisa, que tornaram o caminho até aqui muito mais divertido.

Ao meu orientador Professor Associado Dr. Juliano Souza de Albuquerque Maranhão pela amizade, paciência e dedicação incondicional aos alunos, bem assim pelo contagiante entusiasmo e incentivo à pesquisa de temas tão desafiadores como a Teoria do Direito, a Lógica e o Direito Digital.

Aos colegas dos grupos de estudos DIT - Direito, Incerteza e Tecnologia, e também do GELIAD - Grupo de Estudos de Lógica, Inteligência Artificial e Direito, ambos da Faculdade de Direito da USP e coordenados pelo Professor Juliano Maranhão, cujos ricos debates foram fundamentais para o presente trabalho, especialmente: João Sgarbi, Marcelo Frullani, Artur Péricles, Rafael Saravalli, Guilherme Kenzo, André Moricochi, Fernanda Schmidt, Fabrício Gomes, Paulo Silva, Luís Matricardi, Jorge Alberto e Bruna de Bem.

Aos colegas do Escritório Wald, Antunes, Vita, Longo \& Advogados Associados, a quem agradeço profundamente na pessoa do Professor Arnoldo Wald pelo privilégio de sua convivência, bem assim pelos ricos ensinamentos diários tanto da prática da advocacia quanto da ciência jurídica.

Aos amigos da Turma 171 do curso de Direito do Largo São Francisco, em especial João Paulo Rizek, Euclides Sígoli, Felipe Forte Cobo, Fábio Polli e Flávia Polli, por tantos anos de amizade e cumplicidade.

À Itamara, Lúcio, Henrique, Cristina, Rogério e Débora, demais amigos e familiares pelo carinho, amizade e apoio que desde a tenra juventude tanto contribuíram para o meu desenvolvimento. 


\section{RESUMO}

Pedro de Moura Albuquerque de Oliveira. Reconfiguração conceitual da responsabilidade civil pelo direito digital? 139 páginas. Mestrado - Faculdade de Direito, Universidade de São Paulo, São Paulo, 2018.

O presente estudo se propõe a investigar os possíveis impactos trazidos pelo Direito Digital ao conceito clássico de responsabilidade civil no âmbito do ordenamento jurídico brasileiro, tomando como pano de fundo as profundas transformações socioeconômicas verificadas na virada do século XX para o século XXI decorrentes da revolução tecnológica e extraordinário desenvolvimento dos meios de comunicação de massa, sobretudo após o aparecimento da Internet. Inicialmente, será realizado o estudo das origens históricas da responsabilidade civil até o seu estágio atual no Direito Brasileiro. Será abordado em seguida o desenvolvimento do Direito Digital diante do surgimento da Internet, com a análise das diferentes concepções da rede mundial de computadores como as atreladas à metáfora do ciberespaço e da realidade virtual. Posteriormente, será abordado de modo específico o tema da responsabilidade civil na Internet, com a análise dos principais posicionamentos doutrinários, bem assim dos avanços legislativos que culminaram na edição do Marco Civil da Internet, a Lei $n^{\circ} 12.965 / 2014$. Após, será realizado um estudo sobre a evolução do posicionamento jurisprudencial brasileiro relacionado a casos de responsabilidade civil na Internet; a pesquisa será focada em decisões paradigmáticas constantes de acórdãos proferidos pelo Superior Tribunal de Justiça. Por fim, em sua parte final, o trabalho abordará o papel estratégico dos provedores de serviços de Internet na aplicação do conceito de responsabilidade civil no ciberespaço, bem como os potenciais impactos que desenvolvimento da inteligência artificial poderá trazer à responsabilidade civil em um futuro muito próximo. Neste contexto, o inferencialismo receberá também especial atenção, dado que pode propiciar um entendimento mais adequado do fenômeno linguístico presenciado em um mundo em frenética transformação com o advento da era digital. Ao final, será analisado como o emprego das metáforas pode ser identificado neste possível processo de reconfiguração conceitual da responsabilidade civil, como elo fundamental no transporte de conceitos preexistentes a novas situações até então desconhecidas, por meio da análise de exemplos de casos concretos decididos pelo Superior Tribunal de Justiça.

Palavras-Chave: Reconfiguração conceitual. Responsabilidade civil. Direito digital. Inferencialismo. Metáforas. 


\begin{abstract}
Pedro de Moura Albuquerque de Oliveira. Is digital law revising the concept of civil liability? 139 pages. Master of Laws - Faculty of Law, University of São Paulo, São Paulo, 2018.

This study proposes to investigate the possible impacts of Digital Law on the classic concept of civil liability under the Brazilian legal framework, in light of the profound socioeconomic changes observed during the turn of the $20^{\text {th }}$ century to the $21^{\text {st }}$ century, due to the technological revolution and the extraordinary development of mass communication outlets, chiefly after the onset of the Internet. Primarily, the historic origins of civil liability will be studied, unto its present status under Brazilian Law. Thereafter, the development of Digital Law will be reviewed, in light of the advent of the Internet, encompassing the examination of the different conceptions of the worldwide web of computers, such as those tied to the cyberspace and virtual reality metaphor. Afterward, the issue of civil liability on the Internet will be addressed specifically, with an overview of the main doctrinal postures, as well as the legislative advancements that culminated in the enactment of the Brazilian Civil Rights Framework for the Internet ("Marco Civil"), namely Law no 12,965/2014. Then, the study will look into the evolvement of the Brazilian jurisprudential approach to proceedings concerning civil liability on the Internet; the study will focus on paradigmatic decisions rendered in judgments by the Brazilian Superior Court of Justice. In conclusion, in its final section, the study will address the strategic role of Internet service providers in the application of the concept of civil liability in cyberspace, as well as the potential impacts that the development of artificial intelligence might have on civil liability in the very near future. Within this context, special attention will be paid to inferentialism as well, as it could afford a more appropriate understanding of the linguistic phenomenon within a world that was set into frantic transformation with the advent of the digital era. Lastly, the study will examine how the use of those metaphors can be identified within this likely process of conceptual revision of civil liability as a fundamental link for the shift of preexisting concepts in light of new, unprecedented situations, by examining a number of actual cases tried by the Superior Court of Justice.
\end{abstract}

Keywords: Conceptual revision. Civil liability. Digital law. Inferentialism. Metaphors. 


\section{SUMÁRIO}

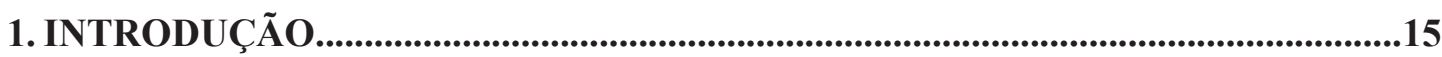

2. O CONCEITO DE RESPONSABILIDADE CIVIL ................................................21

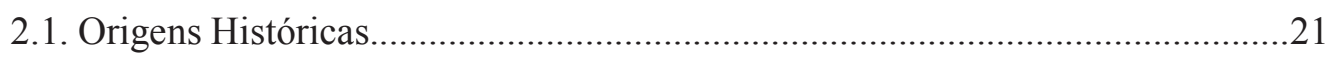

2.2. Evolução no Direito positivo brasileiro...........................................................23

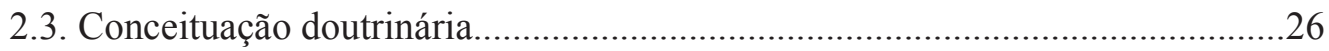

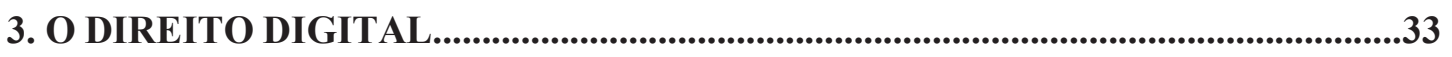

3.1. Revolução digital e desenvolvimento dos meios de comunicação de massa: a

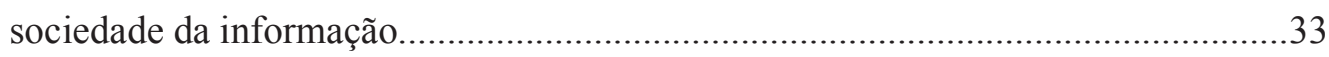

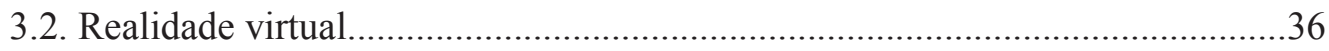

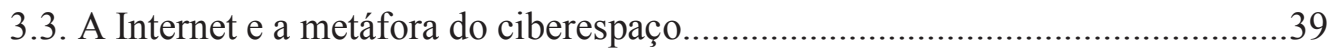

3.3.1. Ciberespaço e Direito...................................................................... 42

3.4. Direito digital como novo ramo do Direito?.................................................46

4. RESPONSABILIDADE CIVIL NA INTERNET...........................................................49

4.1. Definições doutrinárias e as disposições do Marco Civil da Internet..................53

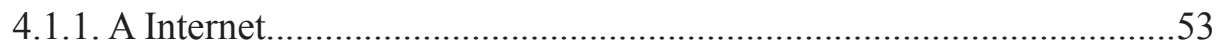

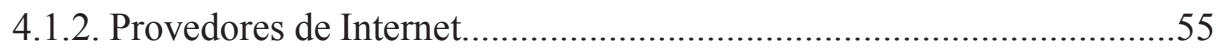

4.1.3. Deveres dos Provedores de Internet................................................58

4.1.3.1. Disponibilização do conteúdo das comunicações..................61

4.1.4. Responsabilidade dos provedores por atos próprios...........................63

4.1.5. Responsabilidade dos provedores por atos de terceiros.....................66

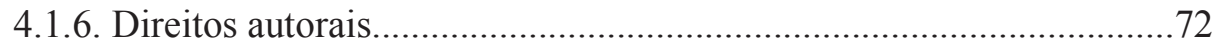

4.2. A jurisprudência do Superior Tribunal de Justiça.............................................73

4.2.1. Provedores de serviços de Internet....................................................74

4.2.2. Aplicabilidade do Código de Defesa do Consumidor........................75

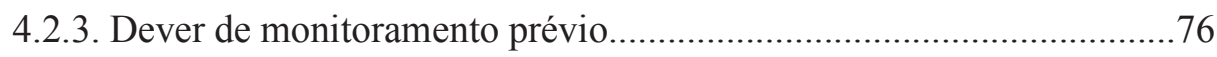

4.2.4. Enquadramento como atividade de risco........................................77 


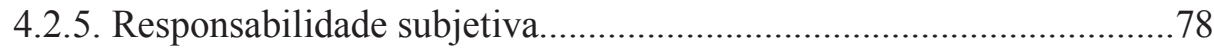

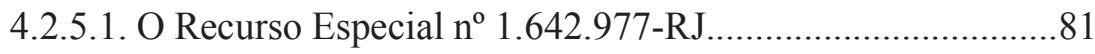

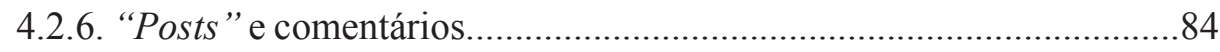

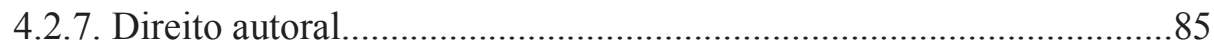

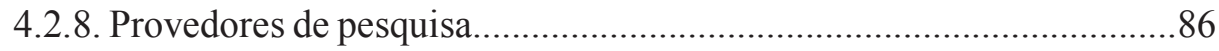

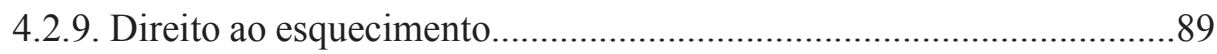

\section{RECONFIGURAÇÃO CONCEITUAL DA RESPONSABILIDADE CIVIL PELO}

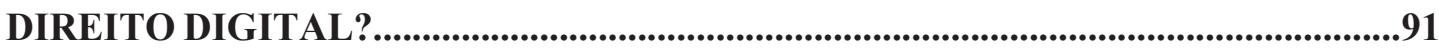

5.1. A inovadora figura do provedor de Internet................................................92

5.2. Os desafios da inteligência artificial...............................................................94

5.3. Inferencialismo e pragmatismo conceitual......................................................98

5.4. Metáforas e reconfiguração conceitual.......................................................... 103

5.4.1. Noção de metáfora, origens e desenvolvimento.................................104

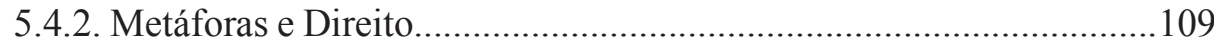

5.4.3. O emprego de metáforas pelo STJ...............................................114

5.4.3.1. Identificação das metáforas...............................................114

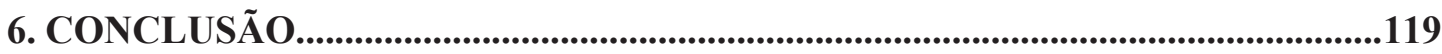

7. BIBLIOGRAFIA...........................................................................................................................125

8. DECISÕES DO SUPERIOR TRIBUNAL DE JUSTIÇA.......................................137

9. DECISÕES DO SUPREMO TRIBUNAL FEDERAL_.........................................139 


\section{INTRODUÇÃO}

O presente estudo se propõe a analisar em que medida o surgimento do Direito Digital, ainda em processo de desenvolvimento inicial tanto no âmbito nacional quanto internacional, impactou ou poderá impactar a responsabilidade civil tal como conceituada e aplicada no contexto do ordenamento jurídico brasileiro. Essa análise assume como pano de fundo as profundas transformações econômico-sociais verificadas na virada do século XX para o século XXI decorrentes da revolução tecnológica e extraordinário desenvolvimento dos meios de comunicação de massa, sobretudo após o aparecimento da Internet, vis-à-vis a importância e relevância social e jurídica da responsabilidade civil, que apresenta rico histórico de transformações e ampliações de sua abrangência para o abarcamento das novas situações fáticas surgidas ao longo dos séculos, que tanto a desafiaram desde sua concepção inicial nos primórdios da civilização.

Inicialmente, será realizada uma investigação quanto às origens da responsabilidade civil ainda em suas primeiras manifestações na antiguidade oriental, passando pelos avanços alcançados no período romano. Após, seguir-se-á rumo à modernidade clássica ocidental, com a abordagem da importante contribuição do Direito Francês ao instituto, com a sua consagração no Código Napoleônico. A partir de então será direcionado o foco da investigação para o Direito Brasileiro, com as primeiras discussões sobre o instituto da responsabilidade civil ainda no período colonial, passando pelo importante Código Civil de 1916, as inovações trazidas pela Constituição Federal de 1988 e a contribuição de legislações especiais, como o Código de Defesa do Consumidor, até a edição do Novo Código Civil, no ano de 2002.

Essa análise da evolução histórica da responsabilidade civil não tem aqui a pretensão de ser exaustiva, tampouco de abranger toda a monumental riqueza dos debates doutrinários travados por uma grande diversidade de notáveis juristas nacionais e estrangeiros sobre o conceito, mas apenas a de delimitar o pano de fundo no qual se insere a problemática atual da aplicação da responsabilidade civil no ambiente digital, e proporcionar bases comparativas para que se possa desenvolver um exercício de identificação de possíveis impactos - atuais e futuros - ao conceito de responsabilidade civil no contexto cada vez mais amplo e abrangente da Internet. 
Será então realizado o estudo do Direito Digital no contexto de seu surgimento, em meio à atual revolução tecnológica em que vivemos, na qual a Internet assume papel central; será assim realizada uma abordagem de suas diferentes concepções, sobretudo as atreladas à metáfora do ciberespaço e da realidade virtual. A relação entre o ciberespaço e o Direito como agente regulador deste novo ambiente será também investigada, assim como a questão do enquadramento do Direito Digital como uma mera ramificação do Direito, ou se na realidade os impactos do mundo virtual ao Direito representam uma amplitude muito maior, com a possibilidade da reconfiguração de seus próprios conceitos fundamentais, como o de responsabilidade civil, foco do presente estudo.

Após, será abordado em profundidade o desenvolvimento do tema da responsabilidade civil na Internet no âmbito do ordenamento jurídico brasileiro. Serão analisados os principais posicionamentos doutrinários acerca do tema, de enorme importância o estabelecimento de uma base conceitual e terminológica mínima indispensável para que os avanços regulatórios posteriores no contexto da Internet pudessem ser alcançados no país. Em conjunto, será também analisado o impacto que a edição do Marco Civil da Internet, a Lei $\mathrm{n}^{\mathrm{o}} 12.965 / 2014$, trouxe à conceituação e aplicação da responsabilidade civil no ambiente virtual, com a sua robusta orientação principiológica e demarcações conceituais importantes, cujas regras vêm sendo gradativamente assimiladas, interpretadas e utilizadas por toda a sociedade.

Após, será realizado um estudo sobre o posicionamento jurisprudencial brasileiro relacionado a casos de responsabilidade civil na Internet; a pesquisa será focada em decisões paradigmáticas constantes de acórdãos proferidos pelo Superior Tribunal de Justiça. Essa opção metodológica se justifica na medida em que apresenta uma amostragem segura dos principais temas relacionados à responsabilidade civil na Internet atualmente debatidos no judiciário nacional, bem como já se mostra temporalmente capaz de refletir o entendimento dessa corte - detentora da última palavra para interpretação de lei federal no país - sobre os temas introduzidos pelo Marco Civil da Internet.

Por fim, em sua parte final, o presente estudo se propõe a realizar uma avaliação dos possíveis impactos ao conceito de responsabilidade civil decorrentes do surgimento do Direito Digital, no contexto das referidas transformações econômico-sociais 
atualmente verificadas em meio à revolução tecnológica e propagação vertiginosa dos meios de comunicação de massa; será então debatido como a difusão da Internet e a sua abrangência cada vez maior em todos os aspectos da vida contemporânea poderiam afetar a concepção dos institutos mais basilares do Direito, com o enfrentamento da arrojada pergunta aqui colocada: Reconfiguração conceitual da responsabilidade civil pelo direito digital?

Nesse contexto, assume extrema relevância o estudo dos provedores de serviços de Internet. Isso porque representam o elo entre todos os usuários e a rede mundial de computadores. A ninguém é dado o acesso direto à Internet, a menos que o faça por intermédio de um provedor. Essa nova sistemática, característica do ambiente virtual, impõe grandes desafios à operacionalização da responsabilidade civil. Como identificar o efetivo agente do ilícito? A quem deve ser imputada a responsabilidade pela reparação do dano? Como apreender claramente o nexo de causalidade entre a ação e o dano reclamado? Questões fundamentais à responsabilidade civil que no ciberespaço passam necessariamente pelas atividades desempenhadas pelos provedores de serviços de internet, fonte de profundas transformações tanto do ponto de vista tecnológico quanto jurídico.

Outra questão fundamental a ser aqui analisada corresponde ao desenvolvimento da inteligência artificial. Fenômeno ainda insipiente, mas que a se confirmarem as previsões mais otimistas sobre os avanços esperados nesta área, a inteligência artificial representará fonte de fortíssimos impactos ao Direito Digital e à responsabilidade civil em um futuro muito próximo. Como o Direito irá se comportar frente a atos ilícitos praticados por robôs, softwares ou computadores capazes de, através de sofisticados algoritmos de aprendizado, ampliar seu conhecimento e tomar decisões de forma independente do seu programador original? Claramente situações como esta não encontram respostas satisfatórias no atual modelo da responsabilidade civil; já existem na atualidade exemplos reais de danos causados por máquinas a terceiros - como acidentes envolvendo veículos automatizados - cuja solução reparatória despertou este iminente debate jurídico no país.

O inferencialismo receberá também especial atenção. Isso porque, em contraste à concepção clássica ontológica, o inferencialismo considera a formação e a 
transformação dos conceitos em uma dinâmica pragmática de uso. Os conceitos jurídicos, nesse contexto, são forjados à medida da aplicação das regras jurídicas a casos concretos, em um processo cíclico. Havendo mudanças nesse cenário, como no caso de surgimento de novas situações ou alterações profundas no ambiente de aplicação das regras, o próprio conceito será igualmente alterado. O inferencialismo pode, assim, propiciar um entendimento mais adequado do fenômeno linguístico presenciado, como importante metodologia para percepção de um mundo em frenética transformação em meio ao advento da era digital.

A investigação, ao final, irá avaliar como o emprego das metáforas pode ser identificado nesse processo de reconfiguração conceitual. Inicialmente concebida na antiguidade clássica como mera figura de linguagem, teorias recentes a elevaram à condição de figura de pensamento, um elo fundamental em tempos de mudanças paradigmáticas no transporte de conceitos preexistentes a novas situações até então desconhecidas. E no contexto da revolução tecnológica em andamento, o emprego das metáforas para o deslocamento de conceitos do mundo físico para o mundo virtual se acentua, a começar pela própria metáfora da Internet como ciberespaço. Será então realizada a análise de casos paradigmáticos julgados pelo Superior Tribunal de Justiça com o intuito de se identificar o emprego de metáforas no desenvolvimento da aplicação do conceito de responsabilidade civil na Internet no âmbito desta Corte, que culminou no julgamento do Recurso Especial $n^{\circ}$ 1.642.997-RJ, de relatoria da Min. Nancy Andrighi, realizado em 12.09.2017, já em estrita consonância com o novo regramento introduzido pelo Marco Civil da Internet.

O presente estudo teve como inspiração e ponto de partida importante artigo de Juliano Maranhão, intitulado Reconfiguração conceitual? O direito digital como metáfora de si mesmo, que será citado e revisitado ao longo de toda a presente dissertação. Nele, o autor levanta o debate sobre os desafios trazidos ao Direito pelo ciberespaço, com exposição instigante acerca do papel das metáforas, da dificuldade de categorizações valorativas e das alterações nas estruturas conceituais dos institutos basilares do Direito, em um contexto no qual a concepção do Direito Digital como mera ramificação do Direito 
preexistente parece não expressar adequadamente a complexidade das transformações socioeconômicas que atravessamos. ${ }^{1}$

\footnotetext{
1 "Mas é na atividade de interpretação que os conflitos no ciberespaço desafiam o direito de forma mais aguda. Esse desafio está presente em três dimensões inter-relacionadas: (i) emprego de metáforas: argumentos construídos a partir de metáforas do mundo físico para o digital são empregados como ferramentas heurísticas para classificar novas tecnologias em categorias já conhecidas presente na legislação ou em precedentes; (ii) sopesamento de valores: dificuldades de categorização levam a argumentos baseados em políticas e valores potencialmente conflitantes ligados à internet (e.g. liberdade de expressão e privacidade); (iii) mudanças de estrutura conceitual: novas formas de produção, criação e relações econômicas, como "creative commons" e "sharing economy", ou novas tecnologias, como agentes eletrônicos, parecem exigir revisão de conceitos jurídicos fundamentais como personalidade jurídica, propriedade e responsabilidade civil.” (MARANHÃO, Juliano. Reconfiguração conceitual? O direito digital como metáfora de si mesmo. In: FORTES, Pedro; CAMPOS, Ricardo; BARBOSA, Samuel (Coord.) Teorias contemporâneas do Direito: o direito e as incertezas normativas. Curitiba: Juruá, 2016, p. 100).
} 


\section{CONCLUSÃO}

Com o estudo da evolução histórica da responsabilidade civil, bem como das principais características do conceito no âmbito da doutrina nacional e internacional, buscouse neste trabalho delimitar o pano de fundo no qual se insere a problemática atual da aplicação da responsabilidade civil no ambiente digital. Desse modo, procurou-se estabelecer, em um primeiro momento do estudo, as bases comparativas para o desenvolvimento de um exercício de identificação de possíveis impactos - atuais e futuros ao conceito de responsabilidade civil no contexto do surgimento do Direito Digital e em meio às transformações decorrentes da revolução tecnológica e extraordinário desenvolvimento dos meios de comunicação de massa vivenciados na passagem do século XX para o século XXI.

Destacou-se, em seguida, o papel central da Internet neste contexto, com a abordagem de suas diferentes concepções, sobretudo as atreladas à metáfora do ciberespaço e da realidade virtual. Foi também investigada a relação entre o ciberespaço e o Direito como agente regulador deste novo ambiente, assim como a questão do enquadramento do Direito Digital como uma mera ramificação do Direito preexistente, ou se na realidade os impactos do mundo virtual ao Direito representam uma amplitude muito maior, com a possibilidade da reconfiguração de seus próprios conceitos fundamentais, como o de responsabilidade civil, objeto da presente pesquisa.

Passou-se então à análise do desenvolvimento da responsabilidade civil na Internet no âmbito do ordenamento jurídico brasileiro, com a abordagem dos principais posicionamentos doutrinários acerca do tema e o relevante impacto que a edição do Marco Civil da Internet, a Lei $\mathrm{n}^{\mathrm{o}}$ 12.965/2014, trouxe à conceituação e aplicação da responsabilidade civil no ambiente virtual; na sequência, foi realizada uma ampla pesquisa focada em decisões paradigmáticas constantes de acórdãos proferidos pelo Superior Tribunal de Justiça relacionadas a casos de responsabilidade civil na Internet, com a abordagem das principais questões pertinentes ao tema atualmente debatidas no judiciário nacional, tendo sido possível inclusive a captação dos reflexos advindos dos novos regramentos introduzidos pelo Marco Civil da Internet. 
Percorrido este caminho inicial, passou-se então ao enfrentamento da arrojada pergunta proposta na presente pesquisa: Reconfiguração conceitual da responsabilidade civil pelo direito digital?

Diante da análise realizada sobre o desenvolvimento da responsabilidade civil na Internet no âmbito nacional, pôde-se notar o enorme esforço legislativo, doutrinário e jurisprudencial realizado no sentido de se encontrar uma abordagem jurídica adequada ao tema, isso com recurso imediato às vertentes do conceito clássico de responsabilidade civil. Todavia, as dificuldades enfrentadas nesta jornada foram tantas que, como visto ao longo desta pesquisa, quase todas as possibilidades teóricas foram testadas até o advento do Marco Civil da Internet, que trouxe certa pacificação conceitual à discussão. Com efeito, conforme reconhecido pelo próprio STJ no julgamento do Recurso Especial no 1.642.997-RJ, de relatoria da Min. Nancy Andrigui, realizado em 12.09.2017, ${ }^{231}$ a hipótese de responsabilização dos provedores de serviços de Internet por atos de terceiros apresentou em passado recente ao menos três soluções absolutamente diversas, quais a sejam: (i) a da total irresponsabilidade dos provedores pela conduta de seus usuários, que atuariam como mero intermediários; (ii) da responsabilidade objetiva dos provedores - decorrente das normas consumeristas ou da teoria do risco -, e finalmente (iii) da responsabilidade subjetiva do provedores, com a subdivisão entre a aplicação do sistema do "notice and take down" e a regra da decisão judicial para retirada de conteúdo introduzida pela Lei nº 12.965/14.

Pôde-se notar, assim, a grande dificuldade do transporte do conceito clássico de responsabilidade civil, ainda que consideradas suas variantes, do mundo físico para o ciberespaço. Extraordinário esforço teórico e argumentativo teve de ser despendido por legisladores, doutrinadores, juízes e operadores do direito em geral para que se pudesse chegar a um arranjo minimamente adequado à aplicação da responsabilidade civil no âmbito da Internet, o qual acabou sendo positivado por meio do Marco Civil. Mas este processo, ao que indicam as evidências obtidas ao longo deste trabalho, ainda está muito distante de

\footnotetext{
231 "No âmbito da jurisprudência dos tribunais brasileiros, conforme exposto pela doutrina, surgiram três entendimentos sobre a responsabilidade civil dos provedores de aplicações de Internet por conteúdos gerados por terceiros: (i) a irresponsabilidade pelas condutas de seus usuários; (ii) a responsabilidade civil objetiva; e (iii) a responsabilidade subjetiva, que pode ser subdividido a partir do momento em que o provedor de aplicação seria responsável pelo conteúdo gerado por terceiro." (STJ - Recurso Especial no 1.642.997-RJ, Rel. Min. Nancy Andrighi - julgado em 12.09.2017).
} 
chegar ao fim no contexto do ordenamento jurídico brasileiro. ${ }^{232} \mathrm{E}$ dando um passo à frente, diante das importantes adaptações que se mostraram necessárias quando da aplicação do conceito clássico de responsabilidade civil ao ambiente virtual e considerando-se ainda que a revolução tecnológica atualmente vivenciada se mantém em acelerado desenvolvimento, mostra-se muito razoável acreditar que em um curto espaço de tempo o próprio conceito clássico de responsabilidade civil poderá sofrer alterações estruturais relevantes.

Ponto que expõe de modo muito evidente esta problemática é a função exercida pelos provedores de serviços de Internet. Como atuam como o elo necessário entre todos os usuários e a rede mundial de computadores, os provedores de serviços de Internet representam uma característica própria do ambiente virtual que impôs como visto enormes desafios, até o presente momento, à operacionalização da responsabilidade civil na rede mundial de computadores. Com a expansão crescente no mundo contemporâneo da influência do ciberespaço na vida cotidiana de todas as pessoas, pensar a conceituação clássica da responsabilidade civil em algumas décadas sem a consideração da possível onipresença dos provedores de serviços de Internet parece pouco provável. Assim, a concepção clássica de uma relação obrigacional indenizatória bilateral (de um lado o autor do ato ilícito e de outra a vítima do dano), parece caminhar para uma relação muito mais complexa de natureza ao menos tripartite, diante da necessária participação dos provedores de serviços de Internet em qualquer assunto relacionado ao mundo virtual, fenômeno que certamente também extrapola as previsões atualmente existentes nas leis civis sobre a responsabilização de terceiros. ${ }^{233}$

\footnotetext{
${ }^{232}$ Vale frisar, conforme ressalta Alessandro Hirata, que o mesmo fenômeno também é percebido em muitos outros países, como na Alemanha: "No tocante à responsabilidade dos provedores, o direito alemão especificou legislativa, doutrinaria e jurisprudencialmente as categorias de provedores, bem como sua específica responsabilidade. Diversos pontos polêmicos foram fixados, como o tipo de responsabilidade, seus elementos subjetivos e objetivos, bem como, por exemplo, os critérios para notificação e responsabilização de conteúdos que violam direitos da personalidade." (HIRATA, Alessandro. Internetrecht: Aspectos de Direito Comparado Alemão. In: Newton de Lucca; Alberto Simão Filho; Cíntia Rosa Pereira de Lima. (Org.). Direito \& Internet III. 1ed.São Paulo: Quartier Latin, 2015, v. 2, p. 618.

${ }^{233}$ Código Cívil de 2002: “Art. 932. São também responsáveis pela reparação civil: I - os pais, pelos filhos menores que estiverem sob sua autoridade e em sua companhia; II - o tutor e o curador, pelos pupilos e curatelados, que se acharem nas mesmas condições; III - o empregador ou comitente, por seus empregados, serviçais e prepostos, no exercício do trabalho que lhes competir, ou em razão dele; IV - os donos de hotéis, hospedarias, casas ou estabelecimentos onde se albergue por dinheiro, mesmo para fins de educação, pelos seus hóspedes, moradores e educandos; V - os que gratuitamente houverem participado nos produtos do crime, até a concorrente quantia."
} 
Outro fenômeno verificado no presente trabalho e que poderá igualmente impactar as bases da conceituação clássica de responsabilidade civil é o crescente desenvolvimento da inteligência artificial. Com efeito, ao se confirmarem as previsões mais otimistas sobre os avanços esperados nesta área, em um curto período de tempo robôs, softwares e computadores serão capazes de, através de sofísticados algoritmos de aprendizado, ampliar seu conhecimento e tomar decisões de forma independente do seu programador original. Claramente situações como esta não encontram respostas satisfatórias no atual modelo da responsabilidade civil; conforme analisado na presente pesquisa, já existem exemplos concretos de danos causados por máquinas a terceiros, como acidentes envolvendo veículos automatizados, cuja solução reparatória despertou este iminente debate jurídico no país. A forma como o direito em geral e o instituo da responsabilidade civil em particular irão lidar com os atos ilícitos praticados de maneira autônoma por máquinas, softwares e robôs ainda deverá ser desenvolvida, mas de todo modo é razoável acreditar que tais desdobramentos, ante à magnitude do evento histórico em questão, deverão afetar sensivelmente a essência de conceitos jurídicos fundamentais, notadamente o de responsabilidade civil.

Nesse contexto, o modo como os conceitos jurídicos fundamentais são impactados diante de profundas transformações socioeconômicas como as atualmente vivenciadas com a revolução tecnológica e o desenvolvimento dos meios de comunicação de massa podem ser melhor compreendidas no âmbito do inferencialismo, concepção teórica que considera a formação e a transformação dos conceitos em uma dinâmica pragmática de uso. Os conceitos jurídicos, no âmbito dessa concepção teórica, são forjados à medida da aplicação das regras jurídicas a casos concretos, em um processo cíclico. Havendo mudanças em um determinado cenário, como no caso de surgimento de novas situações ou alterações profundas no ambiente de aplicação das regras, o próprio conceito será igualmente alterado, em um fenômeno bilateral; assim, ao mesmo tempo em que o conceito de responsabilidade civil sofre adaptações em sua aplicação no âmbito digital, o mesmo pode ocorrer em sentido inverso, com impactos assimilados pelo próprio núcleo do conceito de responsabilidade civil em sua concepção clássica.

Verificou-se ainda a importância das metáforas nesse processo de reconfiguração conceitual. Inicialmente concebida na antiguidade clássica como mera figura 
de linguagem, teorias recentes a elevaram à condição de figura de pensamento, um elo fundamental em tempos de mudanças paradigmáticas no transporte de conceitos preexistentes a situações até então desconhecidas, como um exemplo particular de inferência. E no contexto da revolução tecnológica em andamento, o emprego das metáforas para o deslocamento de conceitos do mundo físico para o mundo virtual se acentuou, a começar pela própria metáfora da Internet como ciberespaço. A análise dos casos concretos julgados pelo STJ e estudados no presente trabalho, como o representado pela decisão paradigmática proferida no julgamento do referido Recurso Especial n 1.642.997-RJ, de relatoria da Min. Nancy Andrighi, realizado em 12.09.2017, revelou o emprego de inúmeras metáforas nos julgamentos que refletem o curso do desenvolvimento até a sedimentação do posicionamento do STJ no tocante à aplicação do conceito de responsabilidade civil na Internet. Com efeito, de forma até mesmo inconsciente, termos e expressões metafóricas tais como "rede social", "comunidade virtual”, "plataforma”, "página pessoal”, "perfil”, "editoração", "responsabilidade editorial”, "site de encontros”, "personalidade virtual”, "ferramenta de buscas", "universo virtual", "portal de noticias", "internautas", "censor digital”, entre muitas outras, foram empregadas pelo STJ no julgamento destes casos, em clara demonstração da utilização dessa figura de pensamento no transporte de conjuntos cognoscitivos e valorativos do mundo físico ao mundo virtual para a resolução de conflitos oriundos da Internet, o que muitas vezes não ocorre sem a verificação de problemas dada à dificuldade inerente a este tipo de transposição.

Da forma como um jurista da virada do século XIX para o século XX, na esteira da revolução industrial, pôde perceber o surgimento do Direito do Trabalho, ${ }^{234}$ um jurista do início do século XXI pode observar com muito mais clareza - em meio às drásticas transformações trazidas pela revolução tecnológica e desenvolvimento dos meios de comunicação de massa - a formação do Direito Digital. Mas as transformações

\footnotetext{
234 “Um jurista na virada do séc. XIX para o século XX talvez tenha percebido de forma menos cataclísmica o surgimento do direito trabalhista apenas como um novo ramo do direito. Mas uma antiga metáfora, "trabalho é um bem (commodity)", crucial para o desenvolvimento da economia de mercado, começava a ser desafiada. O trabalho passava a ser visto como um veículo de integração social que merece proteção e a relação entre empregado e empregador não como aquela de "venda da força de trabalho" por contrato individual, mas como uma relação entre classes sociais, sujeita a regramentos gerais voltados para o equilíbrio de forças. A modificação foi gradativa e encontrou alguns "pontos cegos", como, por exemplo, a punição a sindicatos, nos primórdios do direito concorrencial, por formação de cartel (combinação de ativos). Mas a alteração não ficou circunscrita ao "contrato de trabalho", dado que a doutrina precisaria adequar a própria noção de "contrato", cuja definição, antes calcada na "encontro entre manifestações de vontade livre", passou a incorporar a ideia de "equilíbrio das prestações."” (MARANHÃO, Juliano, 2016, p. 124).
} 
socioeconômicas de hoje, muito mais aceleradas e abrangentes, permitem ao jurista a possibilidade de detectar, com maior grau de acuidade, um fenômeno que pode extrapolar o surgimento de uma nova ramificação jurídica, consistente em uma reconfiguração conceitual abrangente de institutos fundamentais do Direito - como o de responsabilidade civil - cujos elementos indicativos de que este processo possa estar efetivamente em andamento no âmbito do ordenamento jurídico brasileiro constituíram o objeto de investigação da presente pesquisa, com sinalizações positivas - porém ainda não definitivas - neste sentido. 


\section{BIBLIOGRAFIA}

ALCHOURRÓN, Carlos Eduardo; BULYGIN, Eugenio. Introducción a la metodología de las ciencias jurídicas y sociales. Buenos Aires: Astrea y Depalma, 1998.

ALEXY, Robert. Teoria Da Argumentação Jurídica: a Teoria do Discurso Racional como Teoria da Justificação Jurídica. Tradução Zilda Hutchinson Schild Silva. São Paulo: Landy, 2008.

ALMEIDA, Gilberto Martins e MELO, Leonardo de Campos. Identidade e Aplicação do Direito da Informática. Revista da EMERJ, Rio de Janeiro, v. 11, n. 42, 2008.

ALVES, Marco Antônio Sousa. O inferencialismo de Robert Brandom e a rejeição da significação em termos de referência. PERI - Revista de Filosofia, Santa Catarina, v. 2, n. 2, p. 1-14, 2010.

ARISTÓTELES. Poética. São Paulo: Nova Cultural, 1991. (Coleção os Pensadores).

ASCENSÃO, José de Oliveira. Direito da internet e da sociedade da informação. Rio de Janeiro: Forense, 2002.

. Sociedade da informação: estudos jurídicos. Coimbra: Almedina, 1999.

AUSTIN, J.L. How to Do Things with Words. Oxford: Oxford University Press, 1975.

BAKER, G. P.; HACKER, P. M. S. Scepticism, Rules and Language. Blackwell. Oxford: 1984.

BARLOW, John Perry. A Declaration of the Independence of Cyberspace. In: Eletronic Frontier Foundation. Disponível em: https://www.eff.org/cyberspace-independence. 
BEIKER, Sven, CALO, Ryan. Legal Aspects of Autonomous Driving.2010. Disponível em: http://ssrn.com/abstract=2767899.

BIX, Brian H., Defeasibility and Open Texture in The Logic of Legal Requirements, Essays on Defeasibility. Oxford: United Kingdom, 2012. p. 193-201.

BLACK, Max. Metaphor. Proceedings of the Aristotelian Society, New Series, v. 55, p. $273-$ 294, 1954/1955.

BOBBIO, Norberto. O Positivismo Jurídico: Lições de Filosofia do Direito. São Paulo: Ícone, 1995.

BOEGLIN, Jack. The Costs of Self-Driving Cars: Reconciling Freedom and Privacy with Tort Liability in Autonomous Vehicle Regulation. Yale Journal of Law and Technology, v. 17, art. 4, 2015.

BRANCO, Sérgio. Memória e esquecimento na Internet. Porto Alegre: Arquipélago Editorial, 2017.

BRANDOM, Robert B. Articulando Razões. Uma introdução ao inferencialismo. Tradução Agemir Bavaresco [et al.] - Porto Alegre: EDIPUCRS, 2013. . Making it explicit: reasoning, representing, and discursive commitment. Cambridge: Harvard University Press, 2004.

CABELLO, Marcos Antonio Assumpção. Da guarda de registros de acesso a aplicações de internet. In: LEITE, George Salomão; LEMOS, Ronaldo (Coord.). Marco Civil da Internet. São Paulo: Atlas, 2014, p. 711-726.

CARBONI, Guilherme. Direito autoral e autoria colaborativa: na economia da informação em rede. São Paulo: Quartier Latin, 2010.

COHEN, Julie E. Cyberspace as/and space. Columbia Law Review, 107, p. 210-256, 2007. 
COHEN, I. Glenn; BLAVIN, Jonathan H. Gore, Gibson, and Goldsmith: The Evolution of Internet Metaphors in Law and Commentary. Harvard Journal of Law and Technology, v. 16, n. 1, pp. 265, Fall 2002. Disponível em: https://ssrn.com/abstract=479742.

DAVIDSON, D. Inquiries into Truth and Interpretation. New York: Oxford University Press, 1992.

. What Metaphors Mean. In: MARTINICH, A.P. (Ed.) The Philosophy of Language. Third Edition. New York: Oxford University Press, 1996. p. 415-426.

GODOY, Claudio Luiz Bueno de. Uma análise crítica da responsabilidade civil dos provedores na Lei n. 12.965/14 (Marco Civil da Internet). In: DE LUCCA, Newton; SIMÃO FILHO, Adalberto; LIMA, Cíntia Rosa Pereira de (coords.). Direito \& Internet III - Tomo II: Marco Civil da Internet (Lei n. 12.965/2014). São Paulo: Quartier Latin, 2015.

. Liberdade de imprensa e direitos da personalidade. $2^{\mathrm{a}}$ ed. São Paulo: Atlas, 2008.

GRECO, Marco Aurélio. MARTINS, Ives Gandra da Silva. (Org.) Direito e internet: relações jurídicas na sociedade informatizada. São Paulo: Editora Revista dos Tribunais, 2001.

DE LUCCA, Newton; SIMÃO FILHO, Adalberto; LIMA, Cíntia Rosa Pereira de (coords.). Direito \& Internet III - Tomo I: Marco Civil da Internet (Lei n. 12.965/2014) - São Paulo: Quartier Latin, 2015.

. Direito \& Internet III - Tomo II: Marco Civil da Internet (Lei n. 12.965/2014) - São Paulo: Quartier Latin, 2015.

DIAS, José de Aguiar. Da responsabilidade civil. 12. ed. rev., atual., e aumentada por Rui Berford Dias. Rio de Janeiro: Lumen Juris, 2011.

DOMINGUES, Delmar Galisi. O uso de metáforas na computação. Dissertação de mestrado. Escola de Comunicação e Artes da Universidade de São Paulo, 2001. 
DWORKIN, Ronald. Taking Rights Seriously. Cambrige: Harvard University Press, 1997.

. A Matter of Principle. Cambridge: Harvard University Press, 1978.

. Law's Empire. Cambridge: Harvard University Press, 1986.

FERRAZ JR., Tercio Sampaio. Introdução ao estudo do direito: técnica, decisão, dominação. São Paulo: Atlas, 2001.

. Teoria da norma jurídica: ensaio de pragmática da comunicação normativa. Rio de Janeiro: Forense Universitária, 1978.

. GRECO, Marco Aurélio; MARTINS, Ives Gandra (Coord.). A liberdade como autonomia recíproca de acesso à informação in Direito e Internet, Relações jurídicas na sociedade informatizada. São Paulo: Editora Revista dos Tribunais, 2001.p. 241-257.

. A ciência do direito. 2. ed. São Paulo: Atlas, 1980.

. Direito Retórica e Comunicação. São Paulo: Saraiva, 1997.

GIACCHETTA, André Zonaro; MENEGUETTI, Pamela Gabrielle. A garantia constitucional à inviolabilidade da intimidade e da vida privada como direito dos usuários no Marco Civil da Internet. In: LEITE, George Salomão; LEMOS, Ronaldo (Coord.). Marco Civil da Internet. São Paulo: Atlas, 2014. p. 375-391.

GODINHO, Adriano Marteleto; ROBERTO, Wilson Furtado. A guarda de registros de conexão: o marco civil da internet entre a segurança na rede e os riscos à privacidade. In: LEITE, George Salomão; LEMOS, Ronaldo (Coord.). Marco Civil da Internet. São Paulo: Atlas, 2014.p. 737-754.

GOMES, Orlando. BRITO, Edvaldo. Responsabilidade Civil. Rio de Janeiro: Forense, 2011.

GONÇALVES, Carlos Roberto. Responsabilidade Civil.13. ed. São Paulo: Saraiva, 2011. 
GRECO, Marco Aurélio; MARTINS, Ives Gandra Martins (Coord.). Direito e Internet, Relações jurídicas na sociedade informatizada. São Paulo: Editora Revista dos Tribunais, 2001.

GRICE, H.P. Meaning. In: MARTINICH, A.P. (Ed.). The Philosophy of Language. Second Edition. New York: Oxford University Press, 1990, p. 72-78.

. GRICE, Paul. Studies in the Way of Words. Cambridge: Harvard University Press, 1991.

FERREIRA, Ivette Senise; BAPTISTA, Luiz Olavo (Coord.) Novas fronteiras do direito na era digital. São Paulo: Saraiva, 2002.

FINGER, Ingrid. Metáfora e significação. Porto Alegre: EDIPUCRS, 1996. (Coleção Filosofia, n. 46).

HACKER, Peter. Wittgenstein: Understanding and Meaning, Volume 1 of an analytical commentary on the Philosophical Investigations. Blackwell, Chicago: Oxford, and Chicago University Press, 1980.

HART, H. L. The Concept of Law. Oxford: Claredon Press, 2th ed., 1997. (Postscript editado por Penelope A. Bulloch \& Joseph Raz).

. Essays on Bentham: Jurisprudence and Political Theory. New York: Oxford University Press, 1982.

. Definition and Theory in Jurisprudence. Law Quarterly Review, 70, 1954.

. The Ascription of Responsibility and Rights, Proceedings of the Aristotelian Society, 49, 1948-9.

HIRATA, Alessandro. O Facebook e o direito à privacidade. Revista de Informação Legisltiva, v. 201, p. 17-27, 2014. 
. Internetrecht: Aspectos de Direito Comparado Alemão. In: Newton de Lucca; Alberto Simão Filho; Cíntia Rosa Pereira de Lima. (Org.). Direito \& Internet III. 1ed.São Paulo: Quartier Latin, 2015, v. 2, p. 609-618.

. O público e o privado no direito de intimidade perante os novos desafios do direito. In: Cíntia Rosa Pereira de Lima; Lydia Neves Bastos Telles Nunes. (Org.). Estudos avançados de direito digital. 1ed. Rio de Janeiro: Elsevier, 2014, p. 29-37.

JHERING, Rudolf Von. O espírito do direito Romano. Tradução Rafael Benaion. Rio de Janeiro: Alba, 1943.

JORDI, Ferrer Bentrán; RATTI, Giovanni Battista (Ed.). The Logic of Legal Requirements, Essays on Defeasibility. Oxford: Oxford University Press, 2012.

KELSEN, Hans. Teoria pura do direito. 4. ed. Tradução João Baptista Machado. Coimbra: Arménio Amado Ed., 1976.

. O problema da justiça. 3. ed. Tradução João Baptista Machado. São Paulo: Martins Fontes, 1998.

LAKOFF, George e JOHNSEN, Mark. Metaphors We Live By. Chicago: University of Chicago Press, 1980. Afterword, 2003.

LARENZ, Karl. Metodologia da ciência do direito. 3. ed. Tradução José Lamego. Lisboa: Fundação Calouste Gulbenkian, 1997.

LARSSON, Stefan. Metaphors, Law and Digital Phenomena: the Swedish pirate bay court case. International Journal of Law and Information Technology, 21(4), 354-379, 2013. Disponível em: http://ijlit.oxfordjournals.org/ by.

LEONARDI, Marcel. Responsabilidade civil dos provedores de serviços de Internet. São Paulo: Juarez de Oliveira, 2005. 
. A garantia fundamental do direito à privacidade e à liberdade de expressão nas comunicações como condição ao pleno exercício do direito de acesso à internet. In: LEITE, George Salomão; LEMOS, Ronaldo (Coord.). Marco Civil da Internet. São Paulo: Atlas, 2014, p. 621-633.

LESSIG, Lawrence. Code and Other Laws of Cyberspace. New York: Basic books, 1999.

. The future of ideas: the fate of the commons in a connected world. New York: Random House, 2001.

. Code: version 2.0.New York: Basic Books, 2006.

LÉVI, Pierre. O que é o virtual? 2. ed. Tradução Paulo Neves. São Paulo: Editora 34, 2011. . Cibercultura. Tradução Carlos Irineu da Costa. São Paulo: Editora 34, 1999.

. Tecnologias da Inteligência: O futuro do pensamento na era da informática. 2.ed. Tradução Carlos Irineu da Costa. São Paulo: Editora 34, 2010.

LIMA, Cíntia Rosa P. A responsabilidade civil dos provedores de aplicação de internet por conteúdo gerado por terceiro antes e depois do Marco Civil da Internet (Lei n. 12.965/14). Revista da Faculdade de Direito (USP), v. 110, p. 155-176, 2015.

. Comentários ao Recurso Especial n. 997.993 (Rel. Min. Luis Felipe Salomão). Revista do Superior Tribunal de Justiça, v. 240, p. 839-848, 2015.

- Direito ao esquecimento e internet: o fundamento legal no Direito Comunitário europeu, no Direito italiano e no Direito brasileiro. Revista dos Tribunais (São Paulo. Impresso), v. 946, p. 77-109, 2014.

LLOREDA, Jordi Martínez. Semántica inferencialista - Robert Brandom. Dissertação de Mestrado, Lógica e Filosofia da Ciência, Universidade de Valladolid, 2013. 
LOCKE, John. Ensaio acerca do entendimento humano. São Paulo: Nova Cultural, 1999.

LOPES, Marcelo Frullani. A responsabilidade civil de portais de notícias por comentários de usuários. Monografia de conclusão de curso de pós-graduação latu sensu "Direito e Tecnologia da Informação”, Escola Politécnica da Universidade de São Paulo, 2017.

LOPES, Serpa. Curso de direito civil. Rio de Janeiro: Freitas Barros, 1964.

MARTINS, Guilherme Magalhães. Responsabilidade civil por acidente de consumo na internet. São Paulo: Editora Revista dos Tribunais, 2008.

MIRANDA, Pontes. Tratado de direito privado: direto das obrigações. Rio de Janeiro: Editora Borsoi, 1966. Tomo LIII, Direito das Obrigações.

MORGAN, J. L. Observation on the Pragmatics of Metaphor. In: ORTONY, A. (Ed.) Metaphor and Thought. New York: Cambridge University Press, 1979, p. 136-147.

MARTINICH, A. P. A Theory for Metaphor. In: MARTINICH, A.P. (Ed.) The Philosophy of Language. 3th. New York: Oxford University Press, 1996, pp. 427-439.

MARANHÃO, Juliano de Souza Albuquerque. Padrões de racionalidade na sistematização das normas. Tese de Doutorado. 2004.

. Positivismo Jurídico Lógico-Inclusivo. São Paulo: Marcial Pons, 2012.

. Estudos sobre lógica e direito. São Paulo: Marcial Pons, 2013.

. Reconfiguração conceitual? $O$ direito digital como metáfora de si mesmo. In: FONTES, Pedro; CAMPOS, Ricardo; BARBOSA, Samuel (Coord.). Teorias contemporâneas do Direito: o direito e as incertezas normativas. Curitiba: Juruá, 2016. 
. Por que teorizar sobre a teoria do Direito? Prefácio In: RAZ, Joseph; ALEXY, Robert; BULYGIN, Eugenio. Uma discussão sobre a teoria do direito São Paulo: Marcial Pons, 2013, p. 9-37.

. Ambiente virtual transforma profundamente categorias jurídicas. Revista Consultor Jurídico, de 05 de dezembro de 2016. Disponível em: http://www.conjur.com.br/2016-dez5/juliano-maranhao-ambiente-virtual-transforma-profundamente-direito.

MARTINS, Guilherme Magalhães. Responsabilidade civil por acidente de consumo na internet. São Paulo: Editora Revista dos Tribunais, 2008.

MILL, John Stuart. Sistema da lógica dedutiva e indutiva. São Paulo: Abril Cultural, 1979. (Os Pensadores).

MONTEIRO, Washington de Barros. Curso de Direito Civil. 38.ed. São Paulo: Saraiva, 2011. v. 5, Direito das Obrigações. Da responsabilidade Civil, p. 565-646.

ORTONY, A. Metaphor. In: GREGORY, R.L. (Ed.) The Oxford Companion to the Mind. New York: Oxford University Press, 1987. p. 478-481.

PEREIRA, Caio Mário da Silva. Responsabilidade Civil. 11. ed. revista e atualizada por Gustavo Tepedino. Rio de Janeiro: Forense, 2016.

PERELMAN, Chaïm. Lógica Jurídica. Tradução Vergínia K. Pupi. São Paulo: Martins Fontes, 1999.

. The New Rethoric, A Treatise on Argumentation. Notre Dame: University of Notre Dame Press, 2008.

QUINE, W.V. Postscript on Metaphor. In: Theories and Things. Cambridge: Harvard University Press, 1981. p. 187-189. 
. Word and Object. Cambridge: MIT Press, 2013.

RAYMOND W. GIBBIS, JR. (Ed.) The Cambridge Handbook of Metaphor and Thought. New York: Cambridge University Press, 2008.

RAZ, Joseph. Authority, Law and Morality. The Monist, v. 68, n. 3, 1985, p. 295-324.

REALE, Miguel. Lições preliminares de direito. 22. ed. São Paulo: Perspectiva, 1995.

ROBERTO, Enrico. Carros Autônomos no Brasil - Responsabilidade Civil e Novos Desafios Jurídicos. Disponível em: http://baptistaluz.com.br/espacostartup/carros-autonomos-nobrasil-responsabilidade-civil-e-novos-desafios-juridicos/.

ROCHA, Francisco Ilídio Ferreira. Da responsabilidade por danos decorrentes de conteúdo gerados por terceiros. In: LEITE, George Salomão; LEMOS, Ronaldo (Coord.) Marco Civil da Internet. São Paulo: Atlas, 2014. p. 817-845.

RODRIGUES, Sílvio. Reponsabilidade Civil. 20. ed. São Paulo: Saraiva, 2003. v. 4.

SANTOS, Milton. Há mesmo um espaço virtual? Disponível em: http://reverbe.net/cidades/wp-content/uploads/2011/livros/Ha-mesmoumespacovirtual_Mil ton-Santos.pdf

SARTOR, Giovanni. Legal Concepts as inferential nodes and ontological categories. Artificial Intelligence and Law, n. 17, 2009, p. 217-251.

SAUSURRE, Ferdinand. Curso de Linguística Geral. 28. ed. Tradução Antonio Chelini, José Paulo Paes e Izidoro Blikstein. São Paulo: Cultrix, 2012.

SCHREIBER, Anderson. Novas Tendências da Responsabilidade Civil Brasileira. Revista Trimestral de Direito Civil, Rio de Janeiro, n. 22, abr./jun. 2005. 
. Marco Civil da Internet: Avanço ou Retrocesso? A Responsabilidade Civil por Dano

derivado do Conteúdo Gerado por Terceiro. Disponível em: http://www.andersonschreiber.com.br/downloads/artigo-marco-civil-internet.pdf.

SCHERER, Matthew. Regulating Artificial Intelligence Systems: Risks, Challenges, Competencies And Strategies. Harvard Journal of Law \& Technology, v.29, n. 2, 2016, p. 381.

SEARLE, J. Speech Acts: An Essay in the Philosophy of Language. Cambridge: Cambridge University Press, 1969.

. Metaphor. In: ORTONY, A. (Ed.): Metaphor and Thought. Cambridge: Cambridge University Press. 1979.

SILVA, Regina Beatriz Tavares; SANTOS, Manoel J. Pereira. (Org). Responsabilidade civil: responsabilidade civil na internet e demais meios de comunicação. São Paulo: Saraiva, 2012.

. Sistema protetivo dos direitos da personalidade. In: SILVA, Regina Beatriz Tavares; SANTOS, Manoel J. Pereira. (Org). Responsabilidade civil: responsabilidade civil na internet e demais meios de comunicação. São Paulo: Saraiva, 2012, p. 33.

SMITH, Bryant Walker. Proximity-Driven Liability. The Georgetown Law Journal, v. 102, 2014.

SOUZA, Carlos Affonso Pereira de. Responsabilidade civil dos provedores de acesso e de aplicações de internet: evolução jurisprudencial e os impactos da Lei $n^{o}$ 12.695/2014 (Marco Civil da Internet). In: LEITE, George Salomão; LEMOS, Ronaldo (Coord.). Marco Civil da Internet. São Paulo: Atlas, 2014, p. 791-816.

SOUZA, Carlos Affonso; LEMOS, Ronaldo. Marco Civil da Internet: construção e aplicação. Juiz de Fora: Editar, 2016. 
SOUZA, Carlos Affonso; TEFFÉ, Chiara Spadaccini de. Responsabilidade dos provedores por conteúdos de terceiros na internet. Revista Consultor Jurídico, de 23 de janeiro de 2017. Disponível em: http://www.conjur.com.br/2017-jan-23/responsabilidade-provedorconteudo-terceiro-internet.

SOUZA, Sérgio Iglesias Nunes de. Responsabilidade civil e a inteligência artificial nos contratos eletrônicos na sociedade da informação. Revista dos Tribunais, São Paulo, a. 97, n. 877 , p. 27-40, nov. 2008.

TEFFÉ, Chiara Spadaccini de. A responsabilidade civil do provedor de aplicações de internet pelos danos decorrentes do conteúdo gerado por terceiros, de acordo com o Marco Civil da Internet. Revista Fórum de Direito Civil - RFDC, Belo Horizonte, a. 4, n. 10, set./dez. 2015.

TEPEDINO, Gustavo. Prefácio In: MARTINS, Guilherme Magalhães. Responsabilidade civil por acidente de consumo na internet. São Paulo: Editora Revista dos Tribunais, 2008. p. 11-13.

VENOSA, Sílvio. Direito civil: responsabilidade civil. 5. ed. São Paulo: Atlas, 2005.

WALD, Arnoldo. Um novo direito para a nova economia: os contratos eletrônicos e o código civil. In: GRECO, Marco Aurélio; MARTINS, Ives Gandra. (Coord.). Direito e Internet, Relações jurídicas na sociedade informatizada. São Paulo: Editora Revista dos Tribunais, 2001.p. 9-30.

WALD, Arnoldo; GIANCOLI, Brunno Pandori. Direito civil: responsabilidade civil. 3. ed. reform. São Paulo: Saraiva, 2015. v. 7.

WITTGENSTEIN, Ludwig. Investigações Filosóficas. São Paulo: Nova Cultural, 1999. (Coleção os Pensadores). . Tractatus Lógico-Philosophicus. São Paulo: EDUSP, 2002. 


\section{DECISÕES DO SUPERIOR TRIBUNAL DE JUSTIÇA}

Recurso Especial no 566.468-RJ, Rel. Min. Jorge Scartezzini - julgado em 23.11.2004.

Recurso Especial nº 1.308.830-RS, Rel. Min. Nancy Andrighi - julgado em 08.05.2012.

Recurso Especial no 997.993-MG, Rel. Min. Luis Felipe Salomão - julgado em 21.06.2012.

Recurso Especial no 1.316.921-RJ, Rel. Min. Nancy Andrighi - julgado em 26.06.2012.

Recurso Especial n 1.306.066-MT, Rel. Min. Sidnei Beneti - julgado em 17.04.2012.

Recurso Especial n 1.193.764-SP, Rel. Min. Nancy Andrighi - julgado em 14.12.2010.

Agravo Regimental no Recurso Especial n 1.309.891-MG, Rel. Min. Sidnei Beneti - julgado em 26.06.2012.

Agravo em Recurso Especial no 917.162-SP, Min. Ricardo Villas Bôas Cueva - decisão de 01.09.2016.

Recurso Especial $n^{\circ}$ 1.274.971-RS, Rel. Min. João Otávio de Noronha - julgado em 19.03.2015.

Recurso Especial nº 1.512.647-MG, Rel. Min. Luis Felipe Salomão - julgado em 13.05.2015.

Recurso Especial no 1.593.873-SP, Rel. Min. Nancy Andrighi - julgado em 17.11.2016.

Recurso Especial n ${ }^{\circ}$ 1.352.053-AL, Rel. Min. Paulo de Tarso Sanseverino - julgado em 24.03.2015. 
Recurso Especial n 1.642.997-RJ, Rel. Min. Nancy Andrighi - julgado em 12.09.2017.

Recurso Especial nº 1.334.097-RJ, Rel. Min. Luis Felipe Salomão - julgado em 28.05.2013.

Recurso Especial nº 1.335.153-RJ, Rel. Min. Luis Felipe Salomão - julgado em 28.05.2013.

Recurso Especial no 1.406.448-RJ, Rel. Min. Nancy Andrighi - julgado em 15.10.2013. 


\section{DECISÕES DO SUPREMO TRIBUNAL FEDERAL}

Repercussão Geral no Recurso Extraordinário com Agravo nº 833.248-RJ, Rel. Min. Dias Toffoli, julgado em 11.12.2014.

Arguição de Descumprimento de Preceito Fundamental (ADPF) $n^{0}$ 403, Rel. Min. Edson Fachin, aguardando julgamento.

Ação Direta de Inconstitucionalidade (ADIN) no 5527, Rel. Min. Rosa Weber, aguardando julgamento. 